\title{
Respiratory control in infants at increased risk for sudden infant death syndrome
}

\author{
Y A PARKS, ${ }^{*} \mathrm{~J}$ Y PATON, ${ }^{*} \mathrm{C}$ S BEARDSMORE, ${ }^{*} \mathrm{U}$ M MACFADYEN, $\dagger \mathrm{J}$ THOMPSON, \\ P C GOODENOUGH,* AND H SIMPSON*
}

Departments of *Child Health and $¥ O$ phthalmology, University of Leicester, and $†$ Leicester Royal Infirmary

SUMMARY There is much debate relating to possible abnormalities in respiratory control mechanisms in infants considered at increased risk for sudden infant death syndrome (SIDS). The $\mathbf{P}_{\mathbf{0} \cdot 1}$ occlusion technique was used to assess the central respiratory response to hyperoxic hypercapnia during quiet sleep in 21 normal infants, 13 siblings of SIDS victims, and 17 infants with apparent life threatening events. The slope of $\mathrm{P}_{0 \cdot 1}$ plotted against carbon dioxide concentration increased exponentially with age, independent of body weight in each group. Birth weight has a significant effect on slope with a lower weight predisposing to a lower slope. Siblings as a group had a significantly lower slope at any given age than normal infants, whereas the infants who had had apparent life threatening events were not significantly different from the controls. As intragroup variation in both siblings and control groups greatly exceeded the significant intergroup differences observed, the technique cannot identify individual infants as belonging to one or other group.

Considerable interest has been shown in respiratory control mechanisms in infants thought to be at increased risk for sudden infant death syndrome (SIDS). Shannon and Kelly reported resting alveolar hypoventilation and a reduced ventilatory response to hypercapnia in infants who had experienced an apparent life threatening event. ${ }^{1}$ Others have failed to confirm these findings, ${ }^{2-5}$ while Haddad $e t$ al have reported an increased ventilatory response to hypercapnia in infants experiencing apparent life threatening events when compared with controls. ${ }^{6}$ These conflicting results may be due to a number of factors including varying criteria for infant selection, the suitability of comparison groups, differences in the methods used to assess the responsiveness of the respiratory system, and finally the wide variation in response to hypercapnia among normal infants. ${ }^{7}$ The risk of SIDS in such infants has been shown to be slightly increased, particularly in those who 'required' resuscitation. ${ }^{8}$

Investigations of siblings of SIDS have failed to identify any abnormality in the ventilatory responses to hypercapnia. ${ }^{245}$ Studies in this group of infants, however, produce conflicting results with regard to subsequent risk. Petersen et al concluded that there is no significant increase in risk of SIDS once correction has been made for maternal age and the birth order of the infant. ${ }^{9}$ In contrast, Beal and Blundell found that risk is significantly increased in such cases, possibly up to fivefold, when compared with the general population. ${ }^{10}$ This represents a risk for any individual sibling of about one in a 100 .

Minute ventilation is the usual measure of the output of the respiratory system, but has the limitation that it depends on the mechanical properties of the respiratory system which may be impaired in the presence of disease. An alternative measure, the $P_{0.1}$ occlusion pressure, is independent of the flow resistance and compliance of the respiratory system in healthy individuals as during the manoeuvre there is no flow and only a very small change in lung volume, due to decompression. ${ }^{11}$ If this occlusion technique is applied during hyperoxic hypercapnic rebreathing, a measure of central chemoreceptor responsiveness to hypercapnia can be obtained. ${ }^{12}$ We have utilised this technique to assess the central respiratory response to hyperoxic hypercapnic stimulation in infants at 'increased' risk for SIDS and in normal controls.

\section{Subjects and methods}

Fifty one infants were studied successfully during natural sleep: 21 normal controls, 13 siblings of 


\section{Parks, Paton, Beardsmore, MacFadyen, Thompson, Goodenough, and Simpson}

victims of SIDS, and 17 infants who had had an apparent life threatening event (table 1). Attempts were made to study an additional 19 infants who did not settle sufficiently for the test to be performed. The 19 infants who failed to settle comprised eight normal controls, eight siblings of SIDS victims, and three infants suffering from apparent life threatening events (these infants were studied as inpatients with no real limit on the time available for testing). The infants who failed to settle were comparable clinically with those in whom studies were successful. Many appeared to be 'light sleepers' who were readily roused on being touched or handled.

The apparently normal healthy infants volunteered by their parents had no personal or family history of apnoea or respiratory problems or a family history of SIDS. All were growing and developing normally. The siblings were otherwise normal infants born to families that had experienced a previous infant death consistent with SIDS by history and postmortem examination. The remaining infants had all had an apparent life threatening event, for which either vigorous stimulation or mouth to mouth resuscitation had been applied before normal breathing was restarted. The description of episodes in these infants varied considerably. Ten of the 17 successfully studied were said to be cyanotic when found, 10 apnoeic, four pallid, and eight limp or floppy. Parents felt that their action had been life saving. Investigation had failed to show a convincing explanation for these events. ${ }^{13}$

Infants were studied in the evening after a normal feed. A questionnaire was completed with medical, social, and family details. Each infant was weighed and its length measured at the completion of the test. The studies were performed in a quiet darkened room with an environmental temperature of $20-23^{\circ} \mathrm{C}$ with the infants supine or on their sides. Chest movements were recorded by two symmetri- cally placed magnetometers and abdominal movements by a Graseby respiratory sensor placed lateral to the umbilicus. An electrocardiogram was recorded using disposable self adhesive electrodes (Z100-A Medicotest) that were placed on the left and right sides of the chest anteriorly and on the abdomen. An electroencephalogram was recorded from two channels (B1/9 silver/silver chloride electrodes, Specialised Laboratory Equipment) placed sagitally in the frontal and parietal regions, and an electro-oculogram recorded from disposable self adhesive electrodes (C-50-S Medicotest) placed as diagonal pairs by the outer canthus of each eye. An electromyogram was recorded by self adhesive electrodes (C-50-S Medicotest) placed symmetrically beneath the chin overlying the digastric muscle.

These signals were recorded on a Mingograph 81 ink jet 8 channel recorder (Elema Schonander) with a paper speed of $5 \mathrm{~mm} / \mathrm{second}$. Sleep was staged, by an independent observer, using the criteria set out by Anders $e t$ al, as quiet, active, or indeterminate sleep. ${ }^{14}$

Hyperoxic hypercapnic stimulation was achieved using the rebreathing technique of Read. ${ }^{12}$ Infants breathed a mixture of $5 \%$ carbon dioxide in $95 \%$ oxygen through an appropriate sized face mask (Rendell Baker size 1 or 2) from a closed circuit incorporating a Jaeger screen pneumotachograph (linear to $700 \mathrm{ml} / \mathrm{second}$ ) connected to a one litre anaesthetic rebreathing bag. A shutter system separated the pneumotachograph and face mask from the rest of the circuit. Thirty of the tests were performed with an electromechanical solenoid shutter which, when triggered, would close at end expiration. (End expiration was detected when the flow signal reached zero flow.) The remaining 21 tests were performed using an electrically controlled shutter built into the inspiratory limb of a one way

Table 1 Clinical details of infants studied

\begin{tabular}{llll}
\hline & $\begin{array}{l}\text { Normal } \\
\text { controls }\end{array}$ & $\begin{array}{l}\text { Siblings of } \\
\text { SIDS victims }\end{array}$ & $\begin{array}{l}\text { Infants with } \\
\text { apparent life } \\
\text { threatening } \text { event }\end{array}$ \\
\hline $\begin{array}{l}\text { No of infants } \\
\text { Sex ratio (M/F) }\end{array}$ & 21 & 13 & 17 \\
Birth weight (SD) (g) & $10 / 11$ & $5 / 8$ & $11 / 6$ \\
Gestational age (SD) (weeks) & $3300(360)$ & $3400(530)$ & $3400(480)$ \\
Weight at test (SD) (g) & $39 \cdot 7(0 \cdot 86)$ & $40 \cdot 1(0 \cdot 95)$ & $38 \cdot 7(0 \cdot 48)$ \\
Length at test (SD) (cm) & $4900(1290)$ & $5800(980)$ & $5400(1120)$ \\
Decimal age (years) & $56 \cdot 7(4 \cdot 76)$ & $58 \cdot 8(3 \cdot 71)$ & $59 \cdot 5(4 \cdot 76)$ \\
$\quad \begin{array}{l}\text { Median } \\
\text { Range }\end{array}$ & $0 \cdot 14$ & $0 \cdot 20$ & $0 \cdot 19$ \\
\end{tabular}

There were no significant differences between the three groups $(p>0.05)$. 
valve. When triggered this closed the inspiratory limb during expiration.

Both valves had resistance of less than $5 \mathrm{~cm}$ $\mathrm{H}_{2} \mathrm{O} / \mathrm{V} / \mathrm{second}$ at tidal flow rates. No statistical differences were observed between the results obtained from the two systems, and the results were therefore combined.

The concentrations of carbon dioxide and oxygen in the rebreathing bag were recorded continuously by an infrared analyser (Datex CD102 Normocap) with oxygen electrode through which gas was withdrawn and returned to the bag at a constant rate of $50 \mathrm{ml} /$ minute. The analyser was calibrated and its linearity was checked using concentrations of carbon dioxide up to $8 \%$ and thereafter a two point calibration was used on a daily basis.

Pressure generated at the mouth was recorded by a Validyne MP 45 pressure transducer (range \pm 56 $\mathrm{cm} \mathrm{H}_{2} \mathrm{O}$ ) that had a frequency response linear to 10 $\mathrm{Hz}$. The transducer was calibrated with a water manometer before each study.

Flow was recorded by a Furness Micromanometer (range $\pm 10 \mathrm{~cm} \mathrm{H}_{2} \mathrm{O}$ ), calibrated using a specially constructed sine wave pump. The flow signal was integrated electronically to give tidal volume.

These signals were recorded on an ultraviolet recorder (Bryans Southern Instruments Ltd) at a paper speed of 50 or $100 \mathrm{~mm} / \mathrm{second}$ and used for later analysis.

After the infant was switched into the rebreathing system a 20-30 second period was allowed for equilibration after which there was a linear rise in the carbon dioxide concentration in the bag. During this time the concentration of carbon dioxide in the bag was assumed to be in equilibrium with alveolar, arterial, and cerebral carbon dioxide concentrations. The period of rebreathing continued until the carbon dioxide reached $8 \%$ or the infant aroused. The concentration of oxygen in the bag never fell below $40 \%$.

After initial equilibration and when carbon dioxide concentration was equivalent to $38 \mathrm{~mm} \mathrm{Hg}$ the first brief occlusion was performed. Subsequent occlusions were performed at intervals of 20-30 seconds. Triggering ensured that airway occlusion occurred at the onset of inspiration and continued for a maximum of 200 milliseconds. Where possible rebreathing runs were repeated after a recovery period of at least five minutes.

\section{ANALYSIS}

Flow, volume, and mouth pressure were recorded on the ultraviolet recorder and the record was analysed to determine the mouth pressure generated $0 \cdot 1$ second after the onset of inspiration against an occlusion (fig 1).
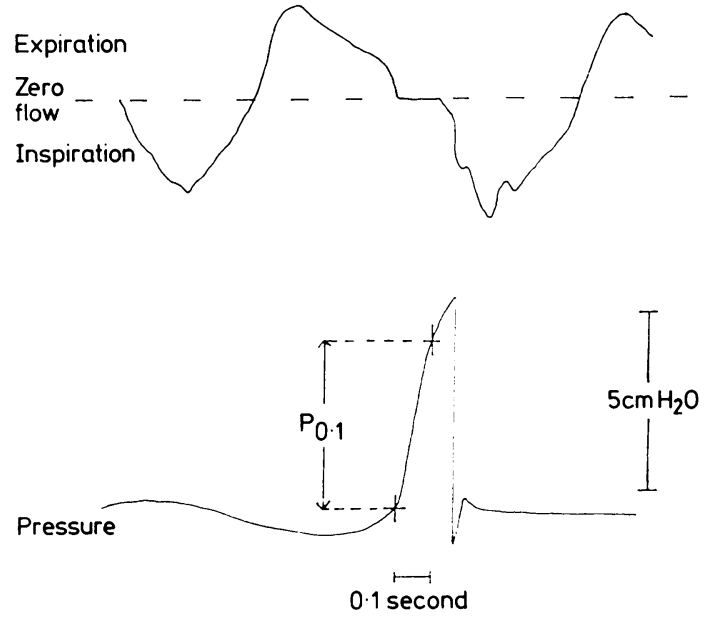

Fig 1 Example of a recording: pressure $0 \cdot 1$ second $(100$ ms) after the onset of inspiration against an occlusion is the Po.l.

A plot of $\mathrm{P}_{0.1}$ against end tidal carbon dioxide tension for each infant showed a linear relation over the range studied. Linear regression was therefore used to calculate the slope of the line $(\mathrm{cm}$ $\mathrm{H}_{2} \mathrm{O} / \mathrm{mm} \mathrm{Hg}$ carbon dioxide) and to define the $\mathrm{P}_{0 \cdot 1}$ at $55 \mathrm{~mm} \mathrm{Hg}$ carbon dioxide $\left(\mathrm{cm}_{2} \mathrm{O}\right)$ in the manner of previous authors. If more than one rebreathing run was obtained in a defined sleep state a common slope was calculated for each infant. Finally, a mean slope and mean $P_{0.1}$ at $55 \mathrm{~mm} \mathrm{Hg}$ carbon dioxide was calculated for each group.

In 10 normal infants minute ventilation was calculated for the three breaths before the occlusion. A plot of minute ventilation against end tidal carbon dioxide tension for each infant showed a linear relationship over the range studied. The slope of this line defined the response to carbon dioxide ( $1 /$ minute $/ \mathrm{kg} / \mathrm{mm} \mathrm{Hg}$ carbon dioxide).

This simple analysis does not take into account the variability in quantity of data obtained from different infants. A minimum recording consisted of three points in a single rebreathing run whereas the maximum recording consisted of 36 data points from a total of six rebreathing runs. Fig 2 shows the variability in the data. Statistical weighting (proportional to the inverse of the variance) was used in the analysis to take account of this variability when combining results for different children. ${ }^{15}$ This method was applied to data for each group and to those of the groups combined.

\section{Results}

As shown by the non-parametric Kruskal-Wallis 


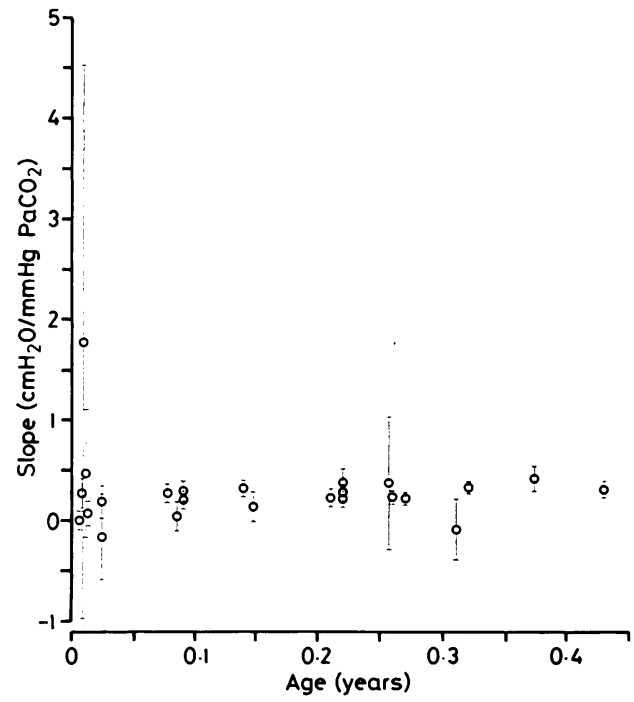

Fig 2 Change in response to carbon dioxide with age in normal infants. Mean (2SD) are shown.

analysis, the three groups of infants were comparable with respect to their birth weight, gestational age, weight, length, and age (table 1 ). The normal infants were studied over an age range 3 days to 6 months, those with an apparent life threatening event from 1 week to 6 months, and siblings of SIDS victims from 6 weeks to 15 weeks.

Recordings were attempted both in quiet sleep and active sleep. Few data were obtained during active sleep and results presented here relate to quiet sleep. For each infant there was a linear relationship between mouth pressure $\left(\mathrm{P}_{0 \cdot 1}\right)$ and end tidal carbon dioxide concentration.

A wide range of slopes was observed within each group ranging from $-0.13 \mathrm{~cm} \mathrm{H}_{2} \mathrm{O} / \mathrm{mm} \mathrm{Hg}$ carbon dioxide to $+0.8 \mathrm{~cm} \mathrm{H}_{2} \mathrm{O} / \mathrm{mm} \mathrm{Hg}$ carbon dioxide. Seventeen of the 21 control infants had a slope between 0 and $0.4 \mathrm{~cm} \mathrm{H}_{2} \mathrm{O} / \mathrm{mm} \mathrm{Hg}$ carbon dioxide. Comparison of the values for slope and $\mathrm{P}_{0.1}$ at 55 $\mathrm{mm} \mathrm{Hg}$ carbon dioxide among the three groups did not show statistical differences. (table 2).

Further analysis of the data using statistical weighting showed an exponential increase in slope with age for all three groups of infants, as follows:

Slope $=0 \cdot 01102+0 \cdot 10354 * \log _{10}($ age $)+0 \cdot 9315 * 10^{-4}$ (weight, g), p <0.05, for control infants;

Slope $=0 \cdot 01102+0 \cdot 10354 * \log _{10}($ age $)+0 \cdot 9315 * 10^{-4}$ (weight, g) $-0.06521, \mathrm{p}<0.01$, for siblings;

Slope $=0 \cdot 01102+0 \cdot 10354 * \log _{10}($ age $)+0.9315 * 10^{-4}$ (weight, g) $-0.05338, \mathrm{p}<0.01$, for infants experiencing an apparent life threatening event.

Intergroup comparison shows that the siblings had a significantly lower value for slope at any given age than the normal infants $(p<0.05)$. The value for slope in the group with an apparent life threatening event did not differ significantly from that obtained in either the normal infants or siblings of SIDS victims (fig 3).

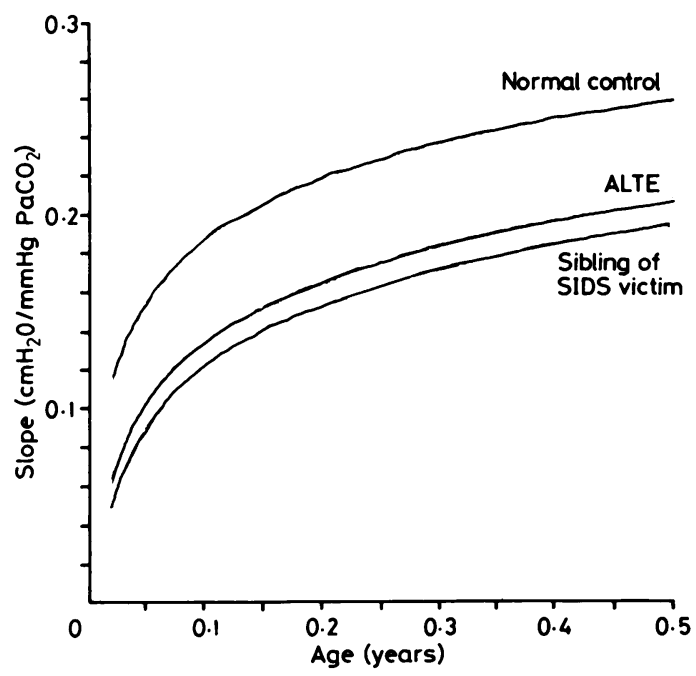

Fig 3 The average slope at different ages for the three groups of infants standardised to a birth weight of $3000 \mathrm{~g}$. ALTE=apparent life threatening event.

Table 2 Summary of the results obtained by simple linear regression

\begin{tabular}{|c|c|c|c|}
\hline & $\begin{array}{l}\text { Normal } \\
\text { controls }\end{array}$ & $\begin{array}{l}\text { Siblings of } \\
\text { SIDS victims }\end{array}$ & $\begin{array}{l}\text { Infants with } \\
\text { apparent life } \\
\text { threatening events }\end{array}$ \\
\hline \multicolumn{4}{|l|}{$P_{0.1}$ slope $\left(\mathrm{cm} \mathrm{H}_{2} \mathrm{O} / \mathrm{mm} \mathrm{Hg}\right.$ carbon dioxide $)$} \\
\hline Median & $0 \cdot 23$ & 0.21 & 0.23 \\
\hline Range & $-0 \cdot 13-0 \cdot 47$ & $0 \cdot 12-0 \cdot 80$ & $0 \cdot 12-0.46$ \\
\hline $\begin{array}{l}\mathrm{P}_{0.1} \text { at } 55 \mathrm{~mm} \mathrm{Hg} \text { carbon dioxide }\left(\mathrm{cm} \mathrm{H}_{2} \mathrm{O}\right) \\
\text { Median (SD) }\end{array}$ & $7 \cdot 12(2 \cdot 51)$ & $8.06(2.81)$ & $8 \cdot 11(2 \cdot 46)$ \\
\hline
\end{tabular}




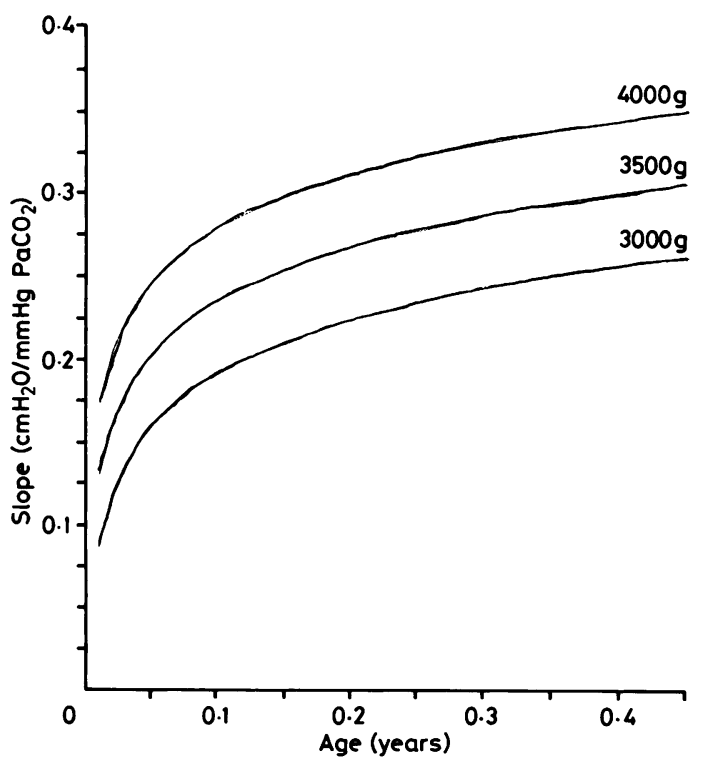

Fig 4 Comparison of response to carbon dioxide in relation to birth weight.

Using multiple regression to assess the influence of weight showed that there was no effect of weight at the time of testing on the age/slope association. Birth weight, on the other hand, exerted a significant effect with a smaller birth weight associated with a lower slope $(p<0.02)$ at any given age (fig 4$)$.

In 10 normal infants we measured minute ventilation and $P_{0.1}$ synchronously in an attempt to compare them as measures of output of the respiratory system. Both indices in these infants showed good correlation with carbon dioxide concentration $\left(P_{0.1}, r=0.913\right.$ and $r=0.954$ for minute ventilation) but that for minute ventilation was significantly stronger $(p<0 \cdot 05)$.

\section{Discussion}

Simple analysis of the data by linear regression shows a range of $P_{0 \cdot 1}$ slope and $P_{0 \cdot 1}$ at $55 \mathrm{~mm} \mathrm{Hg}$ similar to previous studies in adults ${ }^{11}$ and also similar to those of Cosgrove et al who reported a range of slope from $0.2-0.8 \mathrm{~cm} \mathrm{H}_{2} \mathrm{O} / \mathrm{mm} \mathrm{Hg}$ carbon dioxide in nine neonates. ${ }^{16}$

It is only when the variability in the data is taken into consideration that trends become apparent. The response to hypercapnia in infants increases with postnatal age in an exponential fashion. This increase is only $0.2 \mathrm{~cm} \mathrm{H} \mathrm{H}_{2} \mathrm{O} / \mathrm{mm} \mathrm{Hg}$ carbon dioxide over the first six months; this is much smaller than the variability between individual tests. This increase is not simply an effect of weight, which contrasts with the data of Avery et al for infants and adults showing that the ventilatory response to hypercapnia was related to body size rather than age. ${ }^{7}$ It is consistent with the findings of Rigatto $e t$ al who showed a significant increase in ventilatory response in infants 27 days old compared with infants 2 days old. ${ }^{17}$

Our results show that the siblings of SIDS victims have, as a group, a statistically lower response to hypercapnia. Several studies have purported to show an abnormality in the response in the group with an apparent life threatening event ${ }^{618} 19$ but we, in common with others, have not been able to confirm that. ${ }^{2-5}$ Certain other groups of infants considered at increased risk for SIDS, for example, those with apnoea of infancy or those with mothers who are narcotic addicts, show a reduced response to hypercapnia. ${ }^{20} 21$

Although weight at time of testing was not a significant determinant of $\mathbf{P}_{0.1}$ birth weight did exert an effect in that infants of birth weight $3000 \mathrm{~g}$ had a significantly lower slope than those of birth weight $4000 \mathrm{~g}(\mathrm{p}<0 \cdot 02)$.

The effect of the face mask upon the response to carbon dioxide cannot be determined in this study. It has been shown that application of a face mask to a newborn infant leads to an increase in tidal volume and a fall in respiratory frequency, with no significant changes in minute ventilation. ${ }^{22} \mathrm{As}$ it is impossible to measure $P_{0.1}$ without the application of a face mask we cannot speculate on the influence of trigeminal stimulation on our measurements. The conditions of measurement, however, were the same for all three groups so that differences between them should not have been obscured by possible effects of the face mask.

Our data showing a large variation in response among babies as measured by $\mathrm{P}_{0.1}$ slopes (varying from -0.13 to $+0.8 \mathrm{~cm} \mathrm{H}_{2} \mathrm{O} / \mathrm{mm} \mathrm{Hg}$ carbon dioxide) and ventilatory responses in 10 normal infants (varying from 0.014 to $0.052 \mathrm{l} / \mathrm{minute} / \mathrm{kg} / \mathrm{mm}$ $\left.\mathrm{Hg} \mathrm{PaCO}_{2}\right)$ and are in agreement with previous studies. ${ }^{7}$ The significant differences we have shown between siblings and 'normal' infants is small when compared with the variability in the response within each group. Siblings of SIDS victims may therefore be a group in whom respiratory control mechanisms are slightly attenuated. This may simply be a factor in determining their subsequent risk rather than the sole cause of subsequent risk. If the latter were true the occasional infant might have a poor response and the others be within the normal range. The differences are not sufficient to allow identification of individual infants within a particular group. 
The $P_{0 \cdot 1}$ is used as a measure of the neuromechanical output of the respiratory system but before the results can be assessed two potentially important factors must be taken into consideration. ${ }^{23}$ The changes in inspired gas concentrations may influence the level of functional residual capacity and the contractile mechanism of the respiratory muscles. With regard to changes in functional residual capacity Garfinkel and Fitzgerald have shown that hyperoxia decreases it (by $12 \%$ ) while hypercapnia and hypoxia both increase it (by $14-15 \%){ }^{24}$ Changes in functional residual capacity even of this magnitude did not produce any alteration in $\mathrm{P}_{0 \cdot 1} \cdot{ }^{24}$ We did not measure functional residual capacity but as we used a hyperoxic hypercapnic mixture we were unlikely to have produced a significant change in it. In vitro experiments by Fitzgerald $e t$ al have shown that during the brief duration of a rebreathing run the effects of carbon dioxide on muscle contractility are minimal. ${ }^{23}$ We feel that the experimental constraints of our study are unlikely to have altered either functional residual capacity or the contractility of the respiratory muscles.

When comparing recordings of $\mathrm{P}_{0.1}$ and minute ventilation the latter correlated more strongly with carbon dioxide concentration, a finding in agreement with Lederer et al. ${ }^{25}$ It should be noted that in all these infants lung function was assumed to be normal. The possibility remains that in infants with chest disorders the $\mathbf{P}_{\mathbf{0} \cdot \mathbf{1}}$ may be a more representative measure of output than minute ventilation, which could be more affected by mechanical disturbances.

In conclusion, we have shown that the ventilatory response to hyperoxic hypercapnia, as measured by the $P_{0.1}$ occlusion technique, increases in an exponential fashion with postnatal age. This increase is not dependent on weight but is influenced by birth weight. Siblings of SIDS victims have as a group a statistically lower than 'normal' response to hypercapnia whereas the group with an apparent life threatening event of infants does not differ significantly from 'normal'. Whether a 'poor' response to hypercapnia, irrespective of the clinical grouping we have applied, is a risk factor for SIDS is not known.

We should like to thank all the parents and infants involved for their time and patience. We are grateful to Dr P Swift for referring all siblings of SIDS for this study, and to the paediatricians at Leicester Royal Infirmary who referred cases for study. The work was supported by grants from the Foundation for the Study of Infant Deaths and Children Nationwide.

\footnotetext{
References

' Shannon DC, Kelly D. Impaired regulation of alveolar ventila-
}

tion and the sudden infant death syndrome. Science 1977;197: 367-8.

2 Fagenholz SA, O'Connell K, Shannon DC. Chemoreceptor function and sleep state in apnoea. Pediatrics 1976;58:31-6.

3 Ariagno R, Nagel L, Guilleminault C. Waking and ventilatory responses during sleep in infants with near-miss for sudden infant death syndrome. Sleep 1980;3:351-9.

${ }^{4}$ Brady JP, Donovan M, Dumpit FM. Absence of abnormal control of ventilation in infants with aborted sudden infant death syndrome (SIDS). Clin Res 1980;28:128A.

5 Graff MA, Novo RP, Smith C, et al. Ventilatory responses to carbon dioxide in infants at risk for sudden infant death syndrome. Crit Care Med 1986;14:873-7.

6 Haddad GG, Leistner HL, Epstein RA, Epstein MAF, Melnikoff $\mathrm{B}$, Mellins RB. Abnormal breathing pattern and increased ventilatory response to $\mathrm{CO} 2$ in aborted SIDS infants during sleep. Am Rev Respir Dis 1979;119(suppl):269.

7 Avery ME, Chernick V, Dutton RE, Permutt S. Ventilatory response to inspired $\mathrm{CO} 2$ in infants and adults. J Appl Physiol 1963;18:895-903.

8 Oren J, Kelly D, Shannon DC. Identification of a high-risk group for sudden infant death syndrome among infants who were resuscitated for sleep apnoea. Pediatrics 1986;77:495-9.

9 Peterson DR, Sabotta EE, Daling JR. Infant mortality among subsequent siblings of infants who died of sudden infant death syndrome. J Pediatr 1986;108:911-4.

10 Beal SM, Blundell HK. Recurrence of incidence of sudden infant death syndrome. Arch Dis Child 1988;63:924-30.

11 Whitelaw WA, Derenne JPL, Milic-Emili J. Occlusion pressure as a measure of respiratory center output in conscious man. Respir Physiol 1975;23:181-99.

12 Read DJC. A clinical method for assessing the ventilatory response to carbon dioxide. Australasian Annals of Medicine 1967;16:20-32.

${ }_{13}$ Simpson H, MacFadyen UM. Near-miss for sudden infant death syndrome. A clinical approach. In: Meadow R, ed. Recentadvances in paediatrics 8. Edinburgh: Churchill Livingstone, 1986:201-16.

14 Anders T, Emde R, Parmalee A. A munual for standardised terminology and criteria for scoring of states of sleep and wakefulness in newborn infants. Los Angeles: UCLA Brain Information Service, 1971.

15 Palta M, Cook T. Some considerations in the analysis of rates of change in longitudinal studies. Statistics in Medicine 1987;6: 599-611.

16 Cosgrove JF, Neunburger N, Bryan MH, Bryan AC, Levison H. A new method of evaluating the chemosensitivity of the respiratory centre in children. Pediatrics 1975;56:972-80.

17 Rigatto H, Brady JP, Verduzco RT. Chemoreceptor reflexes in preterm infants. II. The effect of gestational and postnatal age on the ventilatory response to inhaled carbon dioxide. Pediatrics 1975;55:614-20.

${ }^{18}$ Shannon DC, Kelly DH, O'Connell K. Abnormal regulation of ventilation in infants at risk for sudden infant death syndrome. N Engl J Med 1977;297:747-50.

19 Hunt CE. Abnormal hypercarbic and hypoxic sleep arousal responses in near miss SIDS infants. Pediatr Res 1981;15: 1462-4.

${ }^{20}$ Gerhardt T, Bancalari E. Apnoea of prematurity. I: Lung function and regulation of breathing. Pediatrics 1984;74:58-62.

${ }^{21}$ Lees MH, Olsen GD, Newcomb JD, Hamel TA. The chemoreceptor responses of infants at high risk for SIDS. In: Tildon JT, Roeder LM, Steinschneider A, eds. Sudden infant death syndrome. London and New York: Academic Press, 1983: 2681-91.

22 Fleming PJ, Levine MR, Goncalves A. Changes in respiratory pattern resulting from the use of a facemask to record respiration in newborn infant. Pediatr Res 1982;16:1031-4.

${ }^{23}$ Fitzgerald RS, Garfinkel F, Silbergeld E, Loscutoff SC. Factors in the interpretation of mouth occlusion pressure during measurements of chemosensitivity. Chest 1976;70:145-9. 
Respiratory control in infants at increased risk for sudden infant death syndrome 797

${ }^{23}$ Garfinkel F, Fitzgerald RS. The effect of hyperoxia, hypoxia and hypercapnia on FRC and occlusion pressure in human subjects. Respir Physiol 1978;33:241-50.

25 Lederer DH, Altose MD, Kelsen SG, Cherniack NS. Comparison of occlusion pressure and ventilatory responses. Thorax 1977;32:212-20.
Correspondence to Professor H Simpson, Department of Child Health, University of Leicester, Clinical Sciences Building, Leicester Royal Infirmary, PO Box 65, Leicester LE2 7LX.

Accepted 5 December 1988 